\title{
LA TEMPORALIDAD DE LA ESCRITURA Y LA SEMÁNTICA DE LA LITERATURA FILOSÓFICA
}

EMILIO LLEdó

U.N.E.D.

La naturaleza que constituye, fundamentalmente, al ser humano ha logrado una determinada forma de originalidad y creatividad con el lenguaje; pero ese supuesto estadio de plenitud «natural» ha implicado, al mismo tiempo, el traspasar las fronteras de esa naturaleza hacia el nuevo territorio de la cultura. Porque un universo silencioso, sin comunicación y sin palabra, no sería ya un universo humano. La sociedad como sistema de referencias y unión entre individuos, es posible por el sutil tejido de informaciones y compromisos que ha creado el lenguaje. Esta unión ha sido precisa para salir de la soledad y el aislamiento que constituye la estructura inevitable y esencial de la individualidad. La clausura que implica la determinación de la funcionalidad biológica del individuo supone, por consiguiente, una limitación. Ser individuo es estar cerrado en la soledad de un organismo que, en su proceso, no depende sino de las leyes de la naturaleza que se concretan en cada ser. Precisamente esta característica de "esencial independencia» marca cualquier forma de vida, principalmente la humana, porque es el egoísmo, como posible denominación de comportamientos enfrentados a la sociabilidad, la expresión de ese conglomerado individual que, en la red de los instintos, defiende la vida de cada ser.

Este simple esquema biológico ha sido el origen de un desarrollo más complicado. El hombre es el animal solitario que, paradójicamente, por defender su soledad y, en consecuencia, su vida, necesita unirse a sus semejantes. Los niveles de integración con los otros, - sea, la sociabilidad, constituyen, con el lenguaje, la esencial característica del ser humano. Polis y Logos, sociabilidad y lenguaje, son, pues, los elementos claves en la constitución del hombre. Pero estos dos elementos se interfieren $y$ se modifican mutuamente. 
Hablar es condición necesaria para que se establezcan los vínculos que forman el tejido social. El lenguaje crea sociedad, pero, a su vez, la sociedad, o sea, el sistema de relaciones que determina las vidas individuales, forma la imprescindible base de la que el lenguaje trota.

Consecuencia de esta conexión entre la base social y la estructura de lenguaje es la imprescindible articulación entre palabra e historia. Esta articulación se produce en toda forma de comunicación linguíistica, por muy abstracta que pueda ser su estructura significante. En consecuencia, no hay Logos que no enraice en la Polis; no hay sistema de signos que no se levante sobre el sistema social, porque no hay "habla" individual que no utilice la lengua colectiva.

Una confirmación de esta tesis podría ser la correspondencia establecida entre los primeros momentos del lenguaje -el origen del lenguaje- y la physis, la naturaleza sobre la que también descansa. Porque, efectivamente, antes de funcionar la Polis, o sea, la sociedad como complicada estructura de tensiones y oposiciones, el ser humano comenzó a regirse por las pautas que la naturaleza le marcaba. Las primeras manifestaciones linguísticas debieron ser señales de ayuda, de colaboración con otros individuos próximos. La naturaleza no sólo hizo posible la emisión de estos sonidos significativos para el otro, sino también permitió que fuese el horizonte natural, ante el que se desarrollaba la vida, el que marcase las «primeras necesidades» del lenguaje, nacido de esos lazos establecidos por individuos que comenzaron a agruparse y a relacionarse.

2. La ciencia lingüística ha distinguido también el peculiar carácter del lenguaje. Tanto Saussure, como posteriormente Chomsky, señalaron, en principio, una doble perspectiva. Por un lado, en el hombre que utiliza una lengua hay una serie de actos individuales ("habla", "actuación») que sobrenadan por el vasto océano de las estructuras colectivas («lengua», «competencia»). Todo acto de habla es, por consiguiente, posible desde un horizonte previo - naturaleza, sociedad, lenguaje- que antecede y condiciona las estructuras del individuo que se expresa. Esta expresión sintetiza, en el tiempo y en el espacio, la materialidad ineludible del habla y de la comunicación.

Reflejo de circunstancias que configuran el discurrir de un ser humano, limitado a sus condiciones precisas de posibilidad y realidad, el lenguaje ha hido marcando la historia y el desarrollo mismo de la humanidad. Lo individual que es el sustento del habla y de la existencia, queda así sumido en el lenguaje, en la masa histórica 
en la que se posa la memoria y en la que encajan los conceptos y las instituciones.

En su larga evolución ese prodigioso invento humano, que sirvió para significar el mundo, y que comenzó siendo un segundo sistema de señales, referido a las cosas a mano y verificado en el contraste con ellas, ha acabado siendo objeto de sí mismo. Desde un simple y limpio reflejo de las cosas y de la vida, en el que se expresó la inmediata relación con la naturaleza, y el impreciso deseo de comunicarla e interpretarla al decirla, el lenguaje se ha convertido en historia solidificada, en memoria colectiva, en realidad ideal, que modifica, utiliza, proyecta, oscurece o aclara a la realidad real. Una ya larga tradición que viene de los sofistas, ha insistido en el carácter del lenguaje como elemento constitutivo del hombre $y$, sobre todo, como componente de su personalidad. Porque, efectivamente, el uso del lenguaje no es el uso de un instrumento extraño a quien lo utiliza. La esencia del hombre como «animal que habla» no define, únicamente, una ambigua y neutra posibilidad de emitir sonidos, de producir una "voz semántica". Ser hombre es ser animal con lenguaje; pero ser tal hombre es adoptar una interpretación del mundo y de la vida sustentada, sobre todo, en diversas perspectivas linguiisticas. Ser individuo humano, personalidad lograda o frustrada, es nombrar el mundo, interpretar - saber interpretar- los hechos "de una cierta manera". Las diferencias que enriquecen o empobrecen a los hombres no son tanto diferencias biológicas, enormemente modestas e insignificantes, sino diferencias linguísticas, que marcan diferencias intelectuales, teóricas y, en consecuencia, diferencias en los comportamientos, en la praxis.

La historia humana es la historia de los lenguajes que la manifiestan, igual que la historia personal es la historia de una determinada forma de aceptación o rechazo de un lenguaje. Por eso el lenguaje, según la expresión de Hölderlin, es un bien peligroso. Su peligrosidad consiste en que sólo a través de él somos hombres, y sólo a través de él podemos condenarnos o salvarnos. Salvación o condena que no se refiere a un destino fuera del tiempo y de la historia, sino dentro; en el fondo de nuestro ser deformado o formado. lúcido $\mathrm{u}$ oscurecido.

3. Por ello la extraordinaria importancia que tiene también el descubrimiento de que, al lado del hombre que habla, ha surgido el hombre que escribe. Esta nueva variante, aparentemente trivial, constituye una forma nueva de cultura. Si se me permite una variación sobre la famosa definición aristotélica, podríamos enriquecerla diciendo que, efectivamente, el hombre es un animal que habla, pero es además un animal que escribe, que es capaz de arrancar 
la palabra de la instantaneidad biológica de su pronunciación, y dejarla fija en un escrito para unos ojos que la entenderán sin necesidad de lengua y labios que la articulen, que la vivan. La escritura marca una etapa decisiva en la consolidación del lenguaje como cultura. Desde el momento en que la expresión lingüística cae en el molde de la palabra escrita, el lenguaje humano experimenta una mutación cualitativa. La instantaneidad temporal que alimenta al lenguaje hablado, y que vive, exclusivamente, en la fugaz cadena de la voz, y en un tiempo que devora, aceleradamente, las significaciones, se cambia en el tiempo largo de la memoria. Las letras coagulan la temporalidad del discurso hablado y lo convierten en un cauce firme, en el que podemos sumergir nuestra subjetividad $y$ el latido concreto de nuestros instantes.

Cada vez que unos ojos se detienen sobre las páginas que recogen el silencioso discurso de un autor ausente, y se renueva el diálogo perdido se enfrentan dos formas originales de temporalidad. Una de ellas participa de una secuencia estable, que conserva el tiempo original del habla, del diálogo interior, del pensamiento, bajo la forma de una cadena de signos siempre presentes en las líneas que constituyen la escritura. La otra forma de temporalidad es instantánea y efímera: la subjetividad de un lector que proyecta sobre la letra el ritmo real, en el que viven sus sentidos y su inteligencia.

Pero este tiempo lento de la escritura ha permitido la consagración del fenómeno literario. Lo que denominamos literatura requería el escrito para organizarse y crecer. La lengua literaria ha sido, pues, posible por la peculiar parsimonia y sosiego que adquiere el lenguaje, cuando no está urgido por la fugacidad del diálogo vivo y puede instalarse en un tiempo que le permite solidificarse y perdurar. Ya Saussure (Curso de lingüística general, Buenos Aires, Losada, 195933, págs. 73-74) había mencionado esta característica de la escritura: «La imagen gráfica de las palabras nos impresiona como un objeto permanente y sólido, más propio que el sonido para constituir la unidad de la lengua a través del tiempo.» Saussure señala, al comienzo de su «Curso», el hecho diferencial de la escritura, antes de que los gramatólogos modernos a lo Derrida destacasen las peculiaridades de la lengua escrita frente a la lengua hablada. El posible prestigio de la escritura se debe también, según Saussure, a que aen la mayoría de los individuos las impresiones visuales son más firmes $\mathrm{y}$ durables que las acústicas, y por eso se atienen de preferencia a las primeras. La imagen gráfica acaba por imponerse a expensas del sonido» (pág. 74). Sin embargo, Saussure no parece insistir en el hecho realmente diferencial. No es sólo que las impresiones visuales sean más firmes que las acústicas, sino que el tiempo del diálogo con la escritura se funda en una asimetría profunda. 
La impresión visual es más firme porque el objeto, que es el centro de la visualización, es un objeto parado, inerte en sus letras. Su discurso no fluye, como la palabra, en el propio tiempo de quien la pronuncia, sino que queda congelado, como discurso total, en las páginas del libro que lo guarda y que está, en un sentido profundo, más allá del tiempo en el que el lector se desgasta y en el que la lengua hablada se consume. Precisamente este reposo es el que, en principio, permite la creación literaria, la literatura como género en el que se expresa una forma peculiar e intensa de lenguaje.

4. La literatura se hace presente como escrito, como lenguaje consolidado en la temporalidad disecada de la letra. Probablemente no habríamos llegado a la literatura como arte, si el lenguaje sólo hubiese existido enhebrado en el hilo temporal que se desgrana, irreversiblemente, al compás con el que el tiempo humano fluye. La palabra hablada sólo podía engranarse en esta cadencia temporal, en la que las sílabas miden, en cierto sentido, al articularse, la fluencia del tiempo. Una silaba pronunciada, una palabra dicha, se pierden para siempre en el pasado, que acoje impasible todos los presentes que constituyen el tiempo, y que sólo duran el instante preciso de su fugaz articulación. Pero la letra queda. El gesto idiomático que se pierde en el fonema emitido, se conserva siempre en el rasgo de la escritura, y se recrea en el diálogo que arrastra consigo mismo y que le permite repensar lo pensado. No hay un tiempo que consuma sus palabras perdidas en el aire. El aire del pensamiento es, en este caso, la escritura.

Por supuesto que todo acto de escritura, sea diálogo o monólogo, procede, en principio, de un autor individual que, a solas con su lenguaje, objetiva en lo escrito el resultado de esa operación intelectual que se denomina reflexión o pensamiento. La escritura es, pues, producto de una mirada sobre el propio lenguaje en la que, por los cauces de un misterioso y complejo discurrir, el filósofo, el escritor, el autor, fija en letras determinados mensajes. Este proceso, a pesar de las posibles clarificaciones que estudios psicológi$\cos$ o epistemológicos hayan podido aportar, es suficientemente oscuro como para que ofrezca un firme reto al deseo de entender lo que otros piensan.

La experiencia del lenguaje natural ofrece una importante muestra del esquema ideal, sobre el que se forma y se orienta el pensamiento. Todo proceso intelectual se inserta en el lenguaje, en el que se expresan determinados estadios de aprendizaje, que han podido llevarse a cabo por los dos territorios que sirven de sustento y contenido a la comunicación: la naturaleza y la sociedad. La naturaleza presta, en principio, el indispensable contraste que otorga 
realidad al lenguaje. Las "primeras" proposiciones fueron, tal vez, referencias a la realidad objetiva. Porque hablar es "hablar de cosas» aunque muchas veces las «cosas" estén seleccionadas y "queridas» por los instintos y los deseos, o sea, por la subjetividad.

Este primer nivel de contraste no hace sino confirmar el originario carácter "natural» del ser humano que necesita, como toda la naturaleza, el ámbito elemental e imprescindible de realidad para existir. Nada brota del hombre y para el hombre que no posea ese inequívoco sello natural. Levantado sobre el suelo de la naturaleza, el animal humano refleja, en el desarrollo de su lenguaje, el hecho de que éste ha sido lentamente construido como versión abstracta y, al fin, intersubjetiva de su experiencia concreta, real, fáctiva, con el mundo que le rodea. Este núcleo inicial de "realidad natural» ha ido ampliándose y desarrollándose a medida que, por el cauce de la intersubjetividad, se ha hecho patente un nuevo territorio sustentador: la presencia de los otros hombres. La naturaleza ha prestado su asiento fundamental a la realidad humana; la sociedad le ha dado, a su vez, la posibilidad de despegarse de la cerrada y fija órbita de las "cosas naturales» para ir adquiriendo, también en sucesivo $\mathrm{y}$ lento desarrollo, lo que constituye su específico dominio de expansión: la cultura. Pero aquí, en el inmenso horizonte de lo cultural, los inmediatos objetivos de un lenguaje surgido paralelamente a la experiencia del mundo han comenzado a mediatizarse, a enriquecerse $y$, desde luego, a difuminarse.

La explosión cultural, el crecimiento de la inteligencia y la sensibilidad empezó a complicar y, por supuesto, a condensar los contenidos de ese lenguaje en el que, principalmente, se asienta la cultura. La lengua hablada $y$, sobre todo, la escritura fueron manifestando niveles de experiencia del mundo y de los hombres. Mientras la temporalidad inmediata del lenguaje hablado marcaba en la comunicación la urgencia misma de esa inmediatez, la lengua escrita, liberada de esas urgencias alusivas a un mundo que no tiene ya por qué estar presente, descansaba en una más pausada forma de temporalidad. Efectivamente, el tiempo del discurso escrito es ya el tiempo de la cultura. Mientras la lengua hablada, a pesar de toda la gama posible de sus referencias, expresa claramente su original atadura a la naturaleza y a la inmediata y próxima realidad, la lengua escrita articula un elemento abstracto que es ya un producto eminentemente humano: el futuro. La intuición de un diálogo con un interlocutor ausente, desconocido e imprevisible, lanza a la experiencia lingüística hacia un mundo nuevo de solidaridad, más allá de la experiencia inmediata del presente y de la inmediata función y ocupación con las cosas a mano. Escribir se convierte así en un acto individual como el hablar, pero justificado por el horizonte de 
la esperanza, del deseo de comunicaciones más amplia, de lejanos interlocutores, de contenidos más intensos.

Al circular lo escrito por dominios más dilatados que los de la inmediatez temporal o espacial adquiere una entidad distinta. La temporalidad mediata de lo escrito, el vasto territorio de esta forma de comunicación, permite también nuevas formas de consolidación de la experiencia. El escrito es un legado para la memoria. En él quedan conservados aquellos descubrimientos de la sensibilidad que, para expresarse, necesitan el tiempo lento del recuerdo y el diálogo interminable con el futuro. Agotado en la instante inmediatez del presente, la lengua hablada "no tiene tiempo» para reposar, modelarse y recoger, en su discurso, las modulaciones de una sensibilidad y una inteligencia que sólo progresan como cultura, o sea, como esquemas integradores de un mosaico intersubjetivo, que coagula sus comunicaciones y experiencias saltando la barrera de la presente, rauda y devoradora temporalidad inmediata. Es cierto que la lengua hablada, precisamente, por esa inmediatez, tiene el poder de estar próxima a la vida, al incesante latido de lo presente, y puede responder a los estímulos directos que constituyen la raíz de la existencia. Sin embargo, estas ventajas apenas lo son frente al lenguaje escrito. Sin él, no habrian perdurado esas experiencias agotadas en el momento mismo de su expresión, y consumidas por la necesidad de justificación en el horizonte real y presente que las provocaba. El lenguaje escrito no era sólo la posibilidad de memoria, sino la consciente empresa sobre la que se levanta la historia y maduran - por eso su peculiar y reposada temporalidad- los descubrimientos humanos. El tiempo inmediato, los estímulos de la existencia derriten el curso del hombre, en la fugaz marcha que marca la instantaneidad; pero la escritura permite que, en el reposo y el silencio requerido para su producción, se sedimente en ella lo que, de otra forma, desapareceria en la irreversible carrera con que el tiempo se desgrana.

5. El mundo que verifica, en principio, el sentido de las proposiciones de un lenguaje es el mundo de la cotidianidad. Es sobre este mundo a mano sobre el que primero contrastó el lenguaje su poder y su necesidad. Después, con la evolución y desarrollo de la sociedad, se fue ampliando a dominios más abstractos y distantes el horizonte de la referencia. Esta ampliación tuvo lugar, sin embargo, a través de la escritura. Porque por muy rica que pudiese ser la comunicación interpersonal en el lenguaje hablado, los estímulos que la provocaban eran, sobre todo, estímulos referidos a un mundo objetivo, común a los hablantes, y circunscrito al ámbito de su inmediata experiencia. Nunca en el encuentro humano que 
condiciona y enmarca el diálogo se dan, en principio, otros condicionamientos que no sean los de la proyección a instancias inmediatas y reales. La idealidad de la que se alimenta la cultura, aunque fuese alumbrada en ese diálogo interpersonal, necesitaba de la escritura para irradiar en el tapiz intersubjetivo, y para sostenerse por encima de la fugacidad de los diálogos sumidos en la vida y en el tiempo inmediato. La irrupción de la identidad en la que se aposentan las experiencias de la intimidad, los deseos y los conocimientos, fue creando ese espacio peculiar del lenguaje que se llama literatura. Los géneros literarios son, pues, manifestaciones de un mundo interior, establecido ya en la cultura y desde la cultura y que organiza, acota y constituye el territorio de la intimidad. Al lado del mundo de la naturaleza, de los objetos reales, se ha ido desplegando, irradiado por el lenguaje, el espacio exclusivamente humano de la cultura. En este espacio de la pura subjetividad, objetivada por la escritura, se abre la manifestación esencial de la memoria, como superación de la temporalidad inmediata, de la instantaneidad que aprisiona y evapora el punzante $y$ atomizado discurrir de la vida.

En este proceso de objetivación del lenguaje y desde la vieja semiótica de Morris nos hemos acostumbrado a definir distintas formas de discurso. Una de estas es la que llamamos discurso literario, literatura. El lenguaje que surge de la naturaleza y de las más urgentes necesidades de la vida, ha ganado, así, unos niveles que no parece que tengan ya que ver con su primitivo origen. Por referirme únicamente a lo que se suele denominar la cultura occidental, podemos afirmar que, desde Grecia, hay una forma de lenguaje que constituye la literatura. Esta forma literaria ha sido posible porque el acto de creación individual pudo mantenerse como letra, como escrito. La pervivencia del instante creador en la escritura ha permitido la salvación de las experiencias pasadas.

Pero ¿qué tipo de experiencias? El lenguaje literario no es un lenguaje "verificable». Su discurso no pretende, fundamentalmente, tener relación inmediata con la realidad. No es reflejo, sino objeto que produce su propia entidad, su propia sustancia. La literatura se aparta, pues, de los moldes originarios del lenguaje, que se fraguaron en el discurso referido a la vida y a las relaciones inmediatas con la necesidad y la solidaridad, para situarse en un mundo con leyes diferentes a aquellas que permitan aplicar a una proposición sus condiciones de verdad o falsedad. Una novela, un poema, no son verdaderos o falsos en función de un contraste con lo real que pueda confirmar o refutar sus asertos. Su valor reside en otros criterios que los que marca esa relación entre proposición y objeto. El lenguaje de la obra literaria está, pues, engarzado en una doble fun- 
ción. Cargado con la semántica de la tradición, el lenguaje literario se encierra en el dominio de su sentido absoluto y concluye aquí su referencia al mundo real. Pero la literatura tiene otra forma de validez. El lenguaje en que se expresa manifiesta la frontera donde se producen los nuevos horizontes y se enriquece la sensibilidad. La validez de la obra literaria se mide en relación con la capacidad que posee su lenguaje de alcanzar una nueva forma de hablar, de comunicarse, sin que el contraste con la realidad tenga que justificar el sentido de lo que dice: un complicado problema de connotación sin referencia, sin objeto; pero, por ello, su verdadero objeto es el lenguaje mismo, el peso del lenguaje.

Las teorías modernas que buscan una explicación del fenómeno literario sobre las exclusivas bases de las teorias lingüísticas, no hacen sino mostrar la radical insuficiencia de estos propósitos. No basta con descubrir complicados engarces de significantes, sutiles relaciones estructurales sobre el tejido de la lengua. La validez literaria se funda en otros supuestos, arrancados del suelo natural y social que impregna toda conducta humana. Estos supuestos no pueden radicar, sin embargo, en lo que constituyen el otro extremo de esta alternativa. Frente a formalismo o estructuralismo, no cabe tampoco destacar un sociologismo sin matices, que atribuyese sentido y validez a la obra literaria sólo en función de su capacidad para expresar los problemas de la sociedad, y las tensiones y luchas de los hombres. Pero, de todas formas, el lenguaje de la literatura es una modificación de la comunicación humana, y en lo más recóndito de su estructura, por muy complicada que pudiera ser, yace siempre el primitivo esquema de un hablar para algo y, sobre todo, para alguien. La frontera de esta comunicación limita con los deseos y los proyectos humanos. Sin embargo, estos límites no abordan al hombre desde inmediatas consignas pragmáticas. Es una frontera imprecisa, ideal, donde las cosas se mueven en un sistema de tensiones en las que desaparece el espesor concreto de la realidad y la naturaleza. Su validez y, por supuesto, su veracidad no es la del contraste. Lo que en la obra literaria se dice no puede verificarse y relacionarse con el mundo a mano. Sus asertos no pretenden la confirmación en una realidad que exprese y que exija niveles de correspondencia. El mundo literario, producto de una actividad libre, sin ataduras a las condiciones implacables de lo real, aparece como un producto absoluto entre las creaciones de los hombres, aunque relativo a ese magma del lenguaje que, naturaleza también, lo alimenta y limita.

6. Entre las formas del lenguaje escrito la fílosofía ha delimitado su parcela. Esta delimitación señala una frontera que, por un 
lado, mira hacia una interpretación coherente de la naturaleza, con ayuda de las experiencias plasmadas en el lenguaje y, por otro lado, deletrea una lectura de los fenómenos alumbrados en la propia subjetividad, que expresan las relaciones del hombre con su mundo $\mathrm{y}$ con los deseos que alientan el silencioso discurso que mueve y constituye su consciencia.

Surgida de la «admiración» - según Platón y Aristóteles nos refieren- 0 de la necesidad de suplir la inestabilidad del hombre desprendido, en parte, de la sólida naturaleza, o de tantas otras posibles instancias que apremian la voz de los filósofos, este problemático e indeciso saber conserva, en lo más profundo y cerrado de su estructura retórica, un engarce con el mundo, con la praxis. La escritura filosófica refleja, en su contextura, un mensaje polícromo, tachonado de propuestas abstractas, de especulaciones ideales que, en el fondo, arrastran materiales muy concretos, anudados a la condición humana y a la naturaleza que, esencial y exclusivamente, ha constituido al hombre. La obra filosófica expresada en un lenguaje, convertida en libro, en comunicación escrita, es un objeto en el que también confluyen diversos materiales. Pero la estructura que estos materiales reciben, ha de tener un fundamento sustentado en el mismo suelo del que emerge la vida, la organización de la naturaleza $y$, por supuesto, la sociedad.

En una perspectiva más ceñida a un autor y a una obra la filosofía se produce en un monólogo interior, pero en un diálogo continuo con otro lenguaje - el de la tradición- que indica temas, orientaciones y condiciones. Por ello una obra filosófica es el eslabón de una cadena; pero un eslabón hecho de una materia en la que se recogen y elaboran piezas y fragmentos de todos los que le han antecedido. Junto a esta manipulación teórica surge una pretensión práctica. En el interior de la filosofía se oculta un diseño ilustrado que, con mayor o menor intensidad, engarza a la teoría con la ética o con la paideia.

El desequilibrio que la razón introduce en la naturaleza y cuyo primer momento de estabilidad inestable es la cultura, requiere una determinada forma de progreso; un dinamismo que sintetiza en sistema de relaciones e iluminaciones, ese espacio de soledad entre la mente y la naturaleza. Por ello toda cultura, y la filosofía en ella, es cultura humana, o sea, cultura creada para compensar el hueco que queda en la naturaleza - como sistema cerrado, perfecto y ciego-, al escapar de ella el hombre, como sistema abierto, imperfecto y lúcido. La filosofía deja oír, pues, el latido de ese desequilibrio, y en él resuena la pretensión de un ideal de inteligencia, de adaptación de la consciencia - fruto de ese desequilibrio- hacia el relativo sosiego que el orden mental pretende y persigue. 
7. Si pudiéramos cuantificar el pensamiento por medio del lenguaje que lo constituye, que es su forma $y$, en cierto modo, también su sustancia, encontraríamos un conglomerado de mensajes, de problemas, de propuestas teóricas y prácticas, surgidas de la tradición filosófica y reelaboradas en distintos presentes, o sea, en distintos momentos históricos, por un determinado autor. La comunicación e inteligencia de esos mensajes presenta abundantes dificultades, pero a pesar de ello están ahí para que, en el futuro de la interpretación, se convierta en diálogo el monólogo que los constituye. La presencia de la obra literaria, nacida en un pasado, arrastra consigo, hacia el futuro, una esperanza de incorporación a otras mentes que al asimilar los contenidos transmitidos incorporen, con ello, la historia, la continuidad y también una importante forma de supervivencia.

En este proceso de hacer dialogar el pasado, la hermenéutica filosófica requiere, hoy más que nunca, un tratamiento adecuado. La tarea inicial de este proceso de inteligencia, consiste en establecer las condiciones de posibilidad de ese diálogo al que el texto nos impulsa. Leer es dialogar, y dialogar sólo es posible cuando se crean los códigos capaces de hacer inteligible ese diálogo. Saber, en definitiva, las proposiciones que forman un discurso escrito. Sin embargo, es difícil precisar el horizonte de alusividad de los lenguajes filosóficos. En primer lugar, porque las referencias de esas proposiciones se vuelcan hacia el mundo interior, en el que se levanta el discurso de la filosofía. No hay, en principio, un mundo objetivo aludido. No hay descripciones o señalizaciones históricas en las que se expresan "hechos», que podemos entender por analogía "real» con aquellos otros que experimentamos en nuestro presente. El lenguaje filosófico es, esencialmente, un discurso de la intimidad. En él, el lenguaje ha perdido ese primer movimiento de reflejo y contraste con un mundo a mano, con un mundo visto. Por ello se puede hablar de "abstracción». Pero precisamente debido a su carácter abstracto el discurso filosófíco es más compacto y absoluto. Si todo lenguaje se inició como un reflejo en el que se vislumbraba, aludido, significado, indicado el mundo; el lenguaje filosófico carece de este constitutivo elemental. Sus significaciones buscan otro tipo de referencia, otro sistema de significaciones que no se justifique por su verificabilidad en lo "real". Pero si un lenguaje tiene sentido ha de poseer una cierta posibilidad de contraste. El cerrado discurso de la filosofía tiene que presentar suficientes fisuras para que, a su través, puedan divisarse "formas" de mundo, estructuras de realidad. El "querer decir» que está en el centro de todo lenguaje, es la pregunta fundamental que ha de dirigirse a la obra filosófica. Ello implica que el autor articula, en sus discursos, una "pretensión", un acto 
de voluntad que además de otorgar sentido al lenguaje en el que se expresa, permite adivinar cuál es el horizonte de alusividad al que apunta y la «realidad abstracta que elabora.

El «querer decir» de la obra filosófica implica una tensión «ilustrada». La filosofía no es sólo una forma de explicación del mundo, de racionalización de los fenómenos, sino que dentro de su sistema teórico cobija un proyecto de comunicación que rebasa la frontera explicativa. Saber es para algo. Tal vez una cierta forma de «liberación». Por supuesto que este término puede convertirse en un tópico vacío en el que únicamente se oculte una fórmula retórica e injustificada. Sin entrar ahora en precisiones sobre su contenido, es evidente que el «querer decir» de las proposiciones filosóficas lleva implícito la búsqueda de una forma superior de explicación en los fenómenos de la naturaleza y la sociedad. Pero explicar es comprometer la mente en un esquema de verificabilidad. Una vez aceptado este esquema la explicación no consiste en la «aquiescencia intelectiva, sino que tras ella alienta un simbolismo práctico, real, que permite levantar toda proposición teórica a un nivel superior de intersubjetividad que, al «producir cultura", aglutina la sociedad e incide en la historia. El acto individual de la escritura, organizado sobre el lenguaje, acepta el compromiso de un instrumento de comunicación cuya significatividad arranca de lo colectivo, y que se ha creado desde los espacios de «realidad» que la sociedad vive.

En el entramado de la literatura filosófica coinciden, pues, distintas clases de materiales. La uniformidad que la escritura ofrece es una uniformidad aparente. Detrás de las proposiciones que van enhebrando el discurso filosófico, se entremezclan los supuestos de una tradición con los presupuestos de la mente individual que los trabaja. Esta mente funciona como proyecto histórico, o sea, como emisora de un lenguaje que modula y condiciona la educación, la biografía, la cultura, la ideología que se sintetiza y personaliza en ella. Cualquiera que sea la distancia histórica a la que se presenta la obra escrita, la tarea de entenderla arranca de la constatación de ese hecho complejo en el que se enmarañan múltiples significados.

8. Un primer enfrentamiento con la escritura fílosófica podría consistir en aislar su terminología. En medio del lenguaje natural en el que se escribe la filosofía, surgen frecuentes módulos significativos que constituyen su bagaje terminológico. La terminología procede de una segregación de los «usos naturales». En ella el autor pretende decir más o decir otra cosa que lo que permite el lenguaje usual. En el «término» de la terminología confluye una intención individual que no recoge, automáticamente, el fluir natural del dis- 
curso. Pulido por el discurrir social, el lenguaje requiere, para individualizarse en la terminología, que el autor sienta como insuficiente e impreciso ese código usual. Pero la terminología necesita ser explicitada en el cauce no terminologizado de la obra filosófica. Sólo haciendo refluir los "términos" en el río del lenguaje que los arrastra, pueden tener significación las intenciones terminológicas de su autor. Sin embargo, el problema planteado por las terminologias, que constituye un problema técnico en la inteligencia de la obra filosófica, es hoy una cuestión marginal. La pretensión de un autor, su importancia y originalidad no puede ya medirse por el calibre terminológico de su lenguaje. La filosofía radica, más bien, en la capacidad que tenga el lenguaje de ser, efectivamente, apto para construir un mundo de significaciones que "verifican» el complejo de significantes de esa escritura. Pero "verificar", en el abstracto universo de la filosofía, es algo distinto del elemental paralelismo que requiere la justificación de una relación y un sentido entre «mundo objetivo" y "proposición". En la filosofía no hay posible configuración de mundo objetivo que pueda decidir sobre la verdad de lo expresado. ¿Cuál puede ser entonces el criterio que establezca los posibles niveles de validez de una filosofía? La respuesta a esta pregunta conduce más allá de los planteamientos terminológicos, hacia un enfoque hermenéutico en el que se busca, precisamente, el mundo oculto detrás del fenómeno alusivo.

El paso previo que inicia la inteligencia de lo escrito consiste en establecer, entre la escritura y el lector, los imprescindibles componentes de un diálogo. Para ello se necesitan dos interlocutores. Entre el libro y el lector ha de establecerse un vínculo que convierta la pasividad del texto, como interlocutor, en una pieza viva que ofrezca lo que todo diálogo precisa: comunidad de código, intercambiabilidad de mensajes y homogeneidad de tiempo. ¿Cómo, sin embargo, puede homogeneizarse el tiempo del diálogo con el pasado? Todo el programa hermenéutico radica en esa recuperación de la voz perdida en el aparente silencio del texto, de la inmediatez imposible ya por las múltiples mediaciones del lenguaje. Pero en un caso como el del lenguaje filosófico, la reconstrucción del mundo aludido es tanto más posible al interlocutor, cuanto más cargado está ese lenguaje de la sustancia histórica y, en cierto modo, real que en él se aglutina. "Sustancia histórica» quiere decir aquí ensamblaje con una tradición y, al mismo tiempo, reelaboración de sus problemas desde la perspectiva de un presente, que convierte sus mediaciones en temporalidad inmediata y su teoría en la praxis necesaria que es todo pensamiento, cuando se enmarca y concreta en una mente individual, en este caso, en la consciencia filosófica. 
Un lenguaje que llega desde el pasado puede considerarse también como resto. Esta visión arqueológica analiza la escritura filosófica como fragmento superviviente de otro tiempo, como conjunto de gestos paralizados en el olvido de su irrecuperable y originario dinamismo. El texto "arqueológico» adquiere solidez y precisión, al considerársele desgajado de cualquier compromiso con el mundo que lo produce y con el universo semántico en el que estuvo inserto. En este caso el intérprete «arqueológico» no pretende el diálogo. Los restos de lenguaje quedan sólo como objetos inertes que pueden ser descritos, analizados, pero nunca "explicados». Su precisión y solidez les da una cierta neutralidad, una indiferencia teórica para ser asumidos como productos singulares, como objetos cuya textura ha quedado cristalizada en todos esos empeños narrativos de la peor historiografía. Asi la cuestión del lenguaje, en cuanto vehículo de experiencia, sensibilidad y conocimientos, queda enfrentada con un proceso homogeinizador que reduce las significaciones a un plano distante, anacrónico y, al fin, ininteligible.

Los productos del pensamiento, sin contexto y sin tiempo, no tienen otra posibilidad de pervivencia e inteligencia que la simple inserción en el museo historiográfico. Aquí el texto es, exclusivamente, un objeto para ser mostrado, una leve señal de pensamiento congelado e inerte en el espacio vacío de una historia singular, lejana y extraña. Disecada en los nervios de su ineludible abstracción, la filosofía acaba asumiendo ese papel que la tradición, más - menos popular, le otorga: una especie de saber incomunicable, un conglomerado de problemas ajenos al tiempo del hombre, al espacio de la sociedad.

Por supuesto que no es sólo culpable de este proceso de momificación la ignorancia de la historia filosófica; los mismos historiadores, los "especialistas» en determinados autores, acaban, muchas veces, por confundir el paisaje de sus objetos filosóficos en una suma de aspectos parciales, en una microhermenéutica que pulimenta la superficie teórica del filósofo, y que lo vuelve irreconocible y sin relieve. Y, sin embargo, ninguna obra teórica, por muy importante que haya sido su componente especulativo, deja de encuadrarse en la sociedad de la que es miembro el individuo que la produce. Por ello la absurda pretensión historiográfica, difuminadora de todos los perfiles en aras de una mayor y más fácil captación de sus objetos, acaba siempre por contar la misma fábula trivial, por asumir en lo irreal las inconfundibles características de la singularidad en la que se expresa la colectividad histórica.

9. Hay argumentos justificados para pensar que la historia de la filosofía es una historia whecha», clausurada ya en su intemporal 
peculiaridad. Apartada a su lugar académico, sólo puede presentar un interés arqueológico en el espacio del museo historiográfico, objeto de contemplación para visitantes desocupados. La sociedad contemporánea, entre la tecnología y el consumo, podría, tal vez, prescindir de la filosofía. Dirimir esta contienda puede resultar, a pesar de todo, reiterativo y estéril, aunque es posible que ese esfuerzo sirviese para clarificar algunas perspectivas de la historia presente.

La tesis fundamental para un intento de nueva lectura se concretaría en el siguiente lema: el texto como pretexto. El problema último que se plantea a toda ciencia de la interpretación es, pues, entender no tanto el texto, sino el motivo que justifica el empeño por una completa y mejor intelección. La vieja polémica entre ciencias de la naturaleza y ciencias de la cultura, entre explicación y comprensión, renovada no hace muchos años, deja siempre sin explicación $\mathrm{y}$, por supuesto, sin comprensión el para qué de esta pretendida y exigida lucidez en la interpretación del pasado. No se trata de buscar utilidad a la aventura hermenética; pero es evidente que las razones de ese empeño por una mejor intelección, han de tener un fundamento distinto del simple gozo especulativo. Porque la especulación y el conocimiento, que empezaron por los sentidos, como Kant nos recuerda, vuelven otra vez a ellos, vuelven a referirse al plano de la realidad y de la existencia. En este plano la teoría y la práctica, las palabras y las cosas se ensamblan en ese concepto que, soterradamente, circula por toda la historia de la filosofía y emerge en sus momentos capitales: la felicidad. Pero esto es ya la afirmación de ese anclaje en la vida, y en los deseos de los hombres con tiempo y con historia.

Probablemente el objeto más importante a través del que se transmite la cultura sea el texto. El texto es un lenguaje elaborado ya desde una perspectiva artística, científica, filosófica, etc. La misión del texto es permitir que la mirada del intérprete pase por él, como por una ventana, hacia el horizonte ideal del sentido. Todo texto es, por consiguiente, pretexto. Producido desde una existencia en el tiempo, desde una individualidad, su carácter abstracto, su estructura simbólica le libran continuamente de cualquier atadura particular. El sentido que el texto articula sólo puede captarse, en su totalidad, como parte de un universo referencial en el que ese texto funciona. En él irrumpen todos aquellos elementos significativos que, por medio del lenguaje, lo convierten en memoria y a su contenido en histórico. Pero en el texto clásico, por ejemplo, la historicidad adquiere un particular relieve. Un texto del siglo xvIr clausura en ese siglo el horizonte de sus referencias. Su carácter histórico se acaba en el momento en que fue escrito. Desde entonces, hasta la posterior lectura de un posible intérprete, el texto es 
absolutamente anacrónico. Pero el comportamiento que el texto tenga con ese inevitable anacronismo le otorga precisamente su carácter de clásico, su plena validez histórica. El carácter terminal de un texto para su propia tradición le abre, sin embargo, una perspectiva inacabada en las mentes que la asumirán posteriormente. El texto superfluo es, por el contrario, aquel cuyo carácter terminal lo es también de sí mismo. Brote exclusivo de una coyuntura histórica al margen del tiempo, su sistema de referencias es incapaz de sobrepasar el propio horizonte temporal. Sólo aquellas obras que logran saltar hasta los sucesivos presentes, desde la clausura del tiempo que cierra su propia historia, son de hecho obras históricas. El carácter histórico no consiste sólo en sintetizar una tradición, sino pervivir ya sin tiempo propio como memoria. Y ello es posible también porque el lenguaje presta, a lo que el texto dice, un sello particular que rompe y amplía la cerrada subjetividad que lo produjo. En este sentido los textos, en el cauce colectivo del lenguaje, irradian un compromiso social, un ámbito plural que enriquece su sentido $\mathrm{y}$ ofrece una clave fundamental para captarlo.

10. Los pasos en dirección al complejo universo de signos que articulan el horizonte temporal de la literatura filosófica podrían esquematizarse en los siguientes puntos:

a) Traducir el problema que el texto expresa a un lenguaje en el que se "actualicen" esos problemas. La posibilidad de esa actualización es un argumento positivo a favor de la validez del texto, de su «pervivencia». Esta traducción ha de evitar, sin embargo, que el texto caiga en un molde que anquilosa su sentido. Las «interpretaciones» de muchas «historias» de la literatura o de la filosofía crean, sobre el discurso del texto original, otro discurso paralelo, trivial e inerte. La filosofía, por ejemplo, se cosifica y objetiva en un lenguaje sin referencias, imposible de ser compartido, de hacerse diálogo. Este carácter clausurado contradice la esencia del lenguaje, de todo lenguaje cuya justificación es referirse a algo, y cuya estructura elemental es la aexigencia» de diálogo. Es evidente que la traducción actualizada puede llevar al descubrimiento de determinados anacronismos. Efectivamente, hay cuestiones filosóficas que sólo alientan dentro del pasado que las originó. El nivel histórico en el que surgieron le prestaba un adecuado contexto para insertarse y "sistematizarse». Pero fuera de ese sistema en el que el texto vive, la filosofía, si no se actualiza, sólo existe ya como objeto de material historiográfico, como objeto de erudición. 
Pero ¿qué es la actualización filosófica? Uno de los rasgos más definitivos de la historia humana es su posibilidad de memoria. La memoria, sin embargo, no es un hecho pasivo. Memoria no es sólo «conservación», sino que a través dc sucesivas incorporaciones a cada presente adquiere su sentido lo «conservado". Sólo así puede entenderse la historia de las ideas. Sin el «continuo» temporal que la sostiene, una memoria no incorporable convertiría a los hechos humanos en simple sucesión de átomos incomunicados y solitarios. Actualizar la filosofía supone, por tanto, ejercitar con ella la elemental operación histórica consistente en ir recogiendo, sucesivamente, las experiencias teóricas de las generaciones pasadas y mirarlas desde la óptica de otros tiempos que asimilan y dan vida, así, a la original constitución del tiempo humano.

b) La reconstrucción de la semántica de un texto filosófico impone una proyección a su espacio histórico. Son diversas las mediaciones que interfieren el lenguaje del texto. La inteligencia de lo que en él se dice requiere la búsqueda de esas mediaciones. No existe un proceso creador que no esté interferido por la personalidad creadora; pero esta personalidad está sostenida por todos aquellos componentes que la constituyen $y$, en cierto sentido, la universalizan. Sociedad, ideología, educación, herencia genética, son factores que «median" al individuo y que hablan, de alguna forma, en la escritura que le expresa. El texto refleja también esas "mediaciones» entre las que destaca aquella que convierte al discurso filosófico en un «mensaje intencional».

c) Si nadie «piensa por pensar», la "finalidad» de la filosofía es una categoría importante para su interpretación. Sin embargo, el "para que» de la filosofía no busca una respuesta que se refiera a su utilidad. El «para qué» es, en este caso, la pregunta por el sentido y orientación del pensamiento y, por ello, los sistemas conceptuales acaban convirtiéndose en índices que marcan las vanguardias del proceso histórico.

d) Los problemas filosóficos no son estáticos. El discurso vertical del propio texto, su sentido como lenguaje inmediato, es asumido por el discurso horizontal de la historia. Así el «para qué" filosófico adquiere una serie de importantes motivaciones. La temporalidad inmediata que se clava en toda obra humana, marcándola con una esencial fugacidad sostenida en el lenguaje, se desliza hacia el futuro que todo texto, toda filosofía, ayuda a constituir. 
e) El texto filosófico, resultado de un proceso que acaba por configurarse en el monólogo interior que lo produce, presenta al intérprete un complejo de mediaciones ocultas en la aparente uniformidad de la escritura. La temporalidad del discurso escrito es temporalidad mediata; pero el hecho de la lectura está sumido en la temporalidad inmediata de unos ojos, de un acto singular que sintetiza también otra forma de temporalidad. La mirada del lector enhebra, en lo leído, las mediaciones de su propia personalidad y de la larga historia que la ha forjado. El texto es un territorio neutral en el que irrumpen dos formas fundamentales de mediación: el pasado cultural con cuyos materiales se ha forjado y el presente del lector que ilumina el texto según la luz de otras particulares y personales mediaciones.

Por ello, toda interpretación del texto de la historia, del gran libro de la cultura, es parecido a ese instrumento musical que convierte en vida los pequeños puntos esparcidos por un papel pautado. El escrito musical sería insonoro si la realidad de un arco, de una cuerda, no interpretase, o sea, no arrancase para el tiempo de la vida el sonido dormido.

Lo mismo pasa con la escritura. Nuestros ojos insertos en la carne, en el mundo, en el tiempo de los latidos, en nuestra propia mentalidad, en nuestro sistema de valores, tropiezan con esas líneas sumidas en otro tiempo inerte, del que sólo quedan esas palabras escritas. Pero el escrito es memoria, y la memoria vive en esos rasgos también sobre el papel, en esas palabras que se despiertan cuando los ojos las encuentran y cuando la mente aprende e interpreta su sentido. 